\title{
Prosthetic fixation in cementless total knee arthoplasty. Influence of techniques, prosthetic design and bone graft enhacement
}

PETER A. KEBLISH

Lehigh Valley Hospital

Hanemann University

\section{SUMMARY}

The knowledge of the biological and mechanical factors which have an influnce in non cemented knee prosthesis' survival and the complexity of the biomechanical (kinematic) demands to which are summitted the different non cemented prosthesis, show the importance of a "natural" solution specially in the field of the substitition of the interposition fibrocartilague structures, such as the meniscus. In the same way it is important to study the behaviourof the different revetment surfaces (Titanium, chrom-cobalt etc..) Lastly, a solid fixation of the implant demands a quality bone, that, in its case, will have come from an autograft.

Key words: Non cemented knee prosthesis. Design. Bony graft.

\section{RESUMEN}

El conocimiento de los factores biológicos y mecánicos que influyen en la supervivencia de las prótesis de rodilla no cementadas y la complejidad de las exigencias biomecánicas (cinemáticas) a las que se someten los diferentes diseños de prótesis no cementadas, indican la importancia de una solución «natural» especialmente en el campo de la sustitución de estructuras fibrocartilaginosas de interposición, tales como el menisco. Asimismo es importante analizar el comportamiento de diferentes superficies de revestimento (Titanio y cromocobalto) p. ej.). Por último, una sólida fijación del implante requiere un hueso de calidad, que, en su caso, deberá proceder de autoinjerto.

Palabras clave: Prótesis de rodilla no cementada. Diseño. Injerto óseo.

\section{INTRODUCTION: THE PROBLEM}

The knee presents a potential hostile environment for joint replacement, with influences of large mechanical forces, altered kinematics, chemical enzyme release, and artificial (metal/plastic/ceramic) articulating surfaces. These factors have been implicated in the most common failure modes in total knee arthroplasty (TKA); namely ultra-high molecular weight polyethylene (UHMWPe) wear, patellar maltracking/loosening, and tibial fixation. Current information suggests that UHMWPe wear particles stimulate the enzymatic cascade which not influence initial fixation (6 weeks to 6 months). In contrast, early fixation failure is due to technique (malalignment), infection, or patellar maltracking.

Cementless fixation of the tibial and patellar components in TKA has become suspect in fixed-bearing designs. Cementless femoral fixation has become accepted because of the high success rates in virtually all series. Cemented fixation has the advantage of immediate fixation, but the known disadvantage of having poor resistance to shear/tension forces. Cemented tibia/patella failures at the bone-metal-plastic interfaces have led to the quest for biologic fixation in order to 1) avoid another material (with inferior properties), 2) allow for osseointegration with the potential for adaptive bone remodeling, and 3) provide long-term fixation. Retrieval analysis (John Collier, PhD., DartmouthThayer School of Engineering) has shown excellent osseointegration in femoral and patellar components with variable (and lower percentage) integration in tibial components. True osseointegration of retrieved (nonfailed) tibial components has been seen in a maximum of $20 \%$ to $30 \%$ of bone prosthetic interface despite normal clinical function and $\mathrm{x}$-ray appearance.

Biologic ingrowth in TKA is technique and design sensitive. Therefore, the success of cementless fixation, especially in the tibia, represents a challenge to the surgeon and prosthetic designers/engineers. Fixed-bearing TKA design presents a dilemma of high contacta stress (increased wear) or high constrained forces (increased loosening). Incongruent round-on-flat or flat-on-flat designs (point contact) are inherently unstable in anteroposterior (AP), mediolateral (ML) and rotation planes. Flat tibial surfaces allow for relatiely unconstrained motion and are accentuated when the posterior cruciate ligament (PCL) is deficient. The potential for rapid wear and failure becomes a reality when articulating surface mismatch increases the stress beyond the manufacture's limits of materials, such as UHMWPe, (which is approximately twenty megaPascales). Highly congruent (fixed-bearing) condylar designs present the opposite efect, namely a translation of higher interface stress to the bone prosthetic interface. Mobility without congruency and/or congruency without mobility, therefore, represents a necessary but less than ideal compromise in fixed-bearing design.

Modular metal-backed tibial components have become the standard in fixed-bearing design. However, failures due to bearing motion at the non-articulating surfa- 
ce are now of increasing concern, especially with thin polyethylene components. Non-articulating bearing motion can lead to microscopic bearing lift-off with initiation of shear forces that exceed the UHMWPe limit. Catastrophic break-through of the polyethylene as well as fracture of the patellar base plates have been seen in personal and reported series, primarily in the thin (lessthan $6 \mathrm{~mm}$ ) and heat pressed point contact devices, such as the Porous Coated Anatomic (PCA).

Screw fixation has become a common mode of securing tibial base plates. Biomechanical studies support the fact that superior «initial fixation» of the upper tibia is accomplished with the use of screws. However, screws and screw holes have the disadvantage of producing problems of metal fretting, corrosion and «cold flow» of UHMWPe. Both of these mechanisms produce wear debris which has ease of access to the screw holes, and can potentially lead to osteolysis, loosenning and failure. An increasing number of these types of failures have been seen, suggesting that screws should be abandoned as a fixation mode in cementless TKA.

\section{THE PATELLAR/FEMORAL ARTICULATION}

Patella problems have emerged as the most common sources of failure in TKA. Prosthetic resurfacing is the norm in many countries and centers. Problems with the prosthetic patella are multifactorial and include: 1) maltracking which leads to subluxation/dislocation, 2) fixation which leads to loosening via osteolysis and fractures, 3 ) polyethylene/metal wear leading to synovitis and potential loosening of all components, and 4) composite dissociation of modular units leading to mechanical failure.

Factors that influence the potencial success or failure of the resurfaced patella include: 1) blood supply (extensive releases), 2) bone bed quality (osteopenia), 3) quadriceps patellar tendon (QPT tracking) mal-alignment, 4) joint line location (technique), 5) position (Baja/Alta), 6) fixation (cement/cementless), and 7) design (fixed dome, fixed anatomic, or moveable anatomic).

The variation in femoral and patellar component design as well as technique must be evaluated by the operating surgeon. Poor femoral design and subtle malalignment problems have lead to a myriad of failures. Selective patellar retention (non-resurfacing) should be considered if risk factors noted above are suspect. Anterior Knee pain and maltracking are the major risk factors with patellar retention. Biologic adaptation and remodeling of the non-resurfaced patella (figure 1) to a reasonably anatomic femoral flange minimizes the many failure modes of the resurfaced patella. Personal experience with patellar resurfacing and non-resurfacing



Figura 1. 


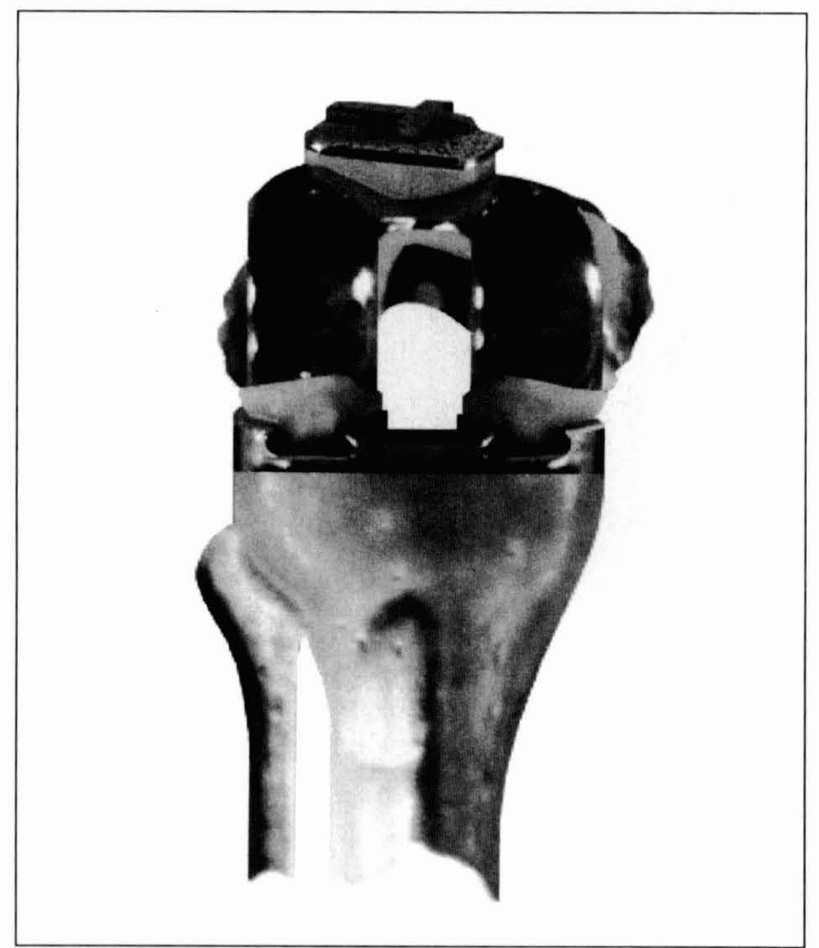

Figura 2. in the same patient has shown equivalent results utilizing the low contact stress (LCS) moveable bearing system. Results of patellar non-resurfacing in over four hundred TKAs with a mean follow-up of 5.5 years has shown a failure rate of less than one-percent. In addition, patellar retention eliminates problems of fixation and UHMWPe wear.

\section{MOVEABLE BEARINGS}

The complexity of Knee biomechanics/kinematics challenges prosthetic knee design. Nature's solution of adaptation to the translational/rotational demandas of knee function are the development of inter-positional fibro-cartilage structures we refer to as menisci. Teleologically (adaptación to a definitive function), the knee menisci allow for: 1) dynamic movement of the femur on the tibia, 2) adaptation to the complex kinematics, 3) increase in articulating surface contact (incongruent to optimally congruent), 4) optimum (lower) contact stress, and 5) protection of hyaline cartilage.

The mechanical analog to menisci, from a prosthetic standpoint, are moveable bearings. This concept was developed by the Oxford Group (Good fellow) with the uni-compartment, and extended by the New Jersey Group (Buechel, Pappas) to a total knee system. The
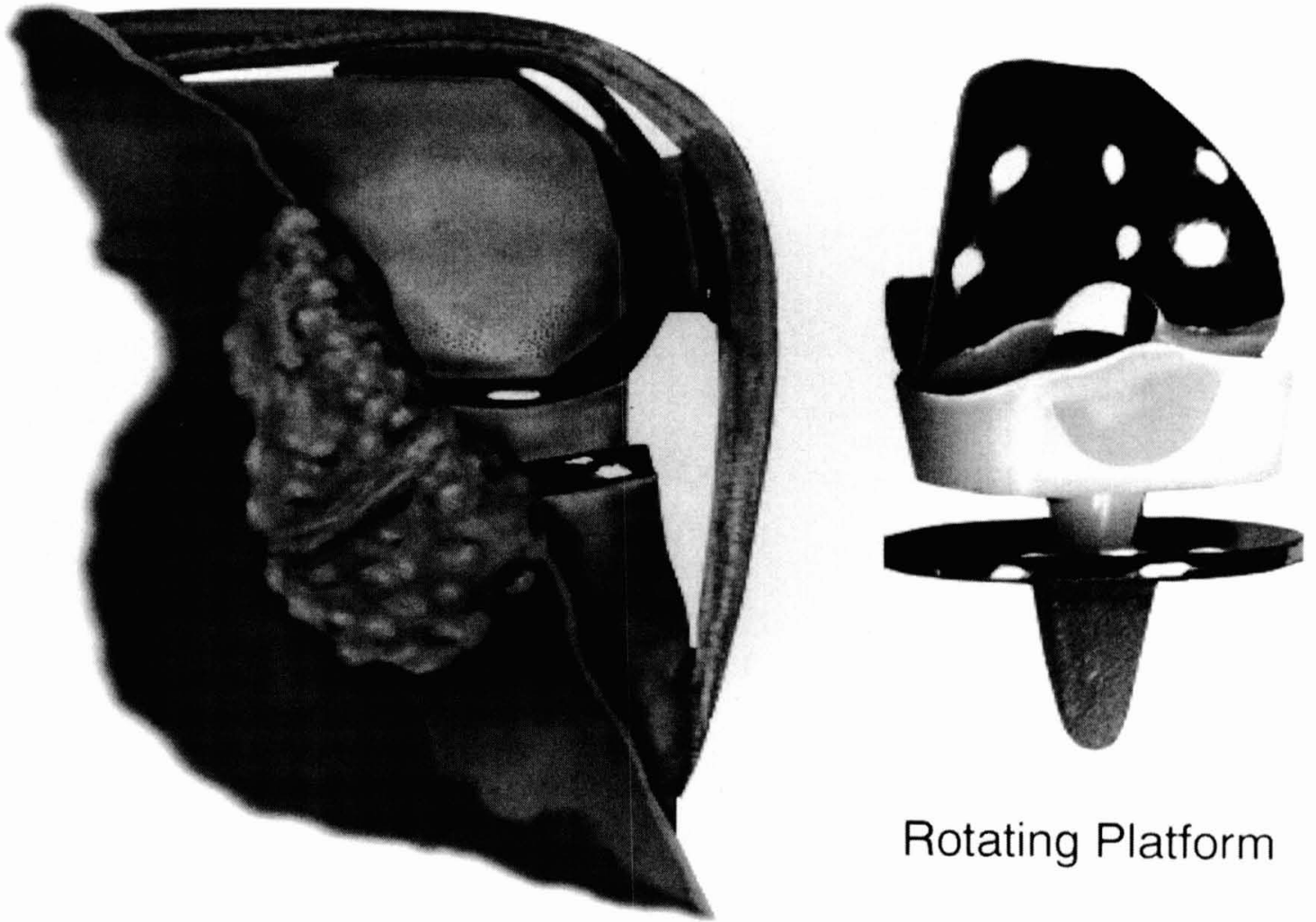

Rotating Platform

Figura 3. 
LCS $_{\text {(New Jersey) }}$ knee system addresses the dilemma of fixed-bearing design. Articular congruity is provided by «matching» generating curves (in the AP and ML planes). Mobility is provided by allowing meniscal bearings to translate in dovetail radial tracks when the PCL is functional, (figure 2), or rotate around a central stem when the PCL is deficient, (figure 3 ). A rotating anatomic patellar design (FIgue 4) allows adaptation to the femoral flange, improving patellar-femoral tracking and stability while decreasing contact stresses. Patellar fixation has provern to be predictable in both cemented and cementless multi-center LCS trials, with less than onepercent overall complication rate $(2 \%$ of which were related to fixation). Fixation and wear are related to congruency and stability at the femoral-tibial and the patellar-femoral articulations. Incongruent design, thin UHMWPe and metallica backed patella components can accentuate minor maltracking and lead to increased, and sometimes rapid, failure in an otherwise well aligned TKA.

The surface treatment of cementless devices varies with different prosthesis. Titanium fiber mesh continues to be used, however, cobalt chrome porous coatint with bead sizes between 125-550 micra (Porocoat (Depuy, $_{\text {, }}$ Warsaw, Indiana) has the longest clinical experience. The Porocoat processing affords a proud surface, $(1-2 \mathrm{~mm})$ which allows for improved implant fixation stability.

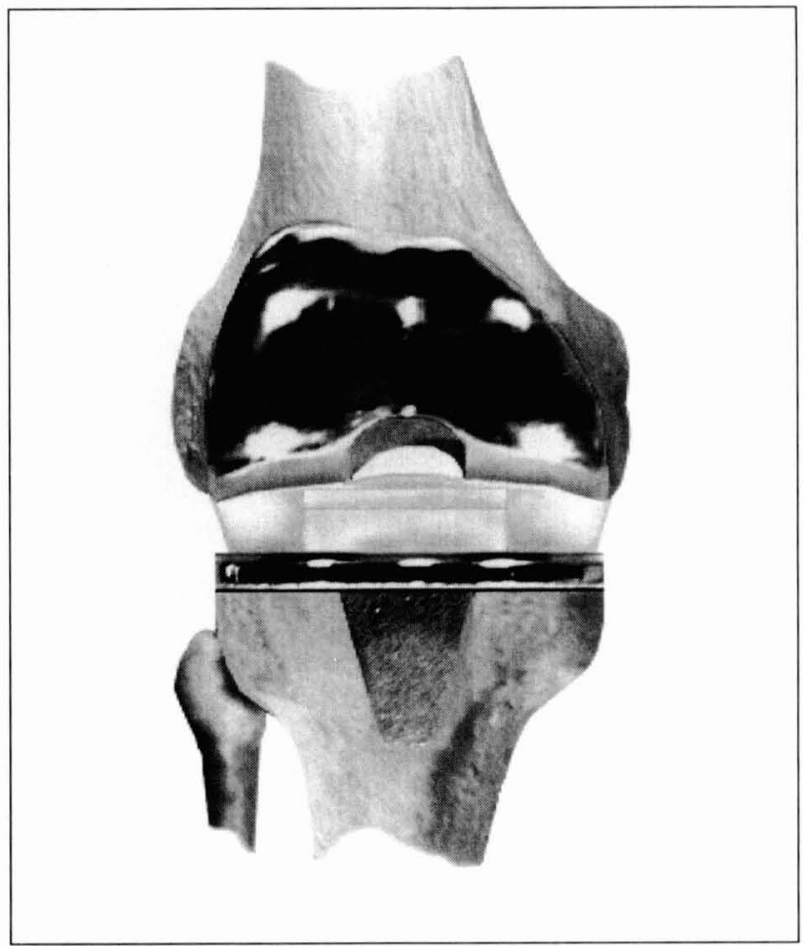

Figura 5.

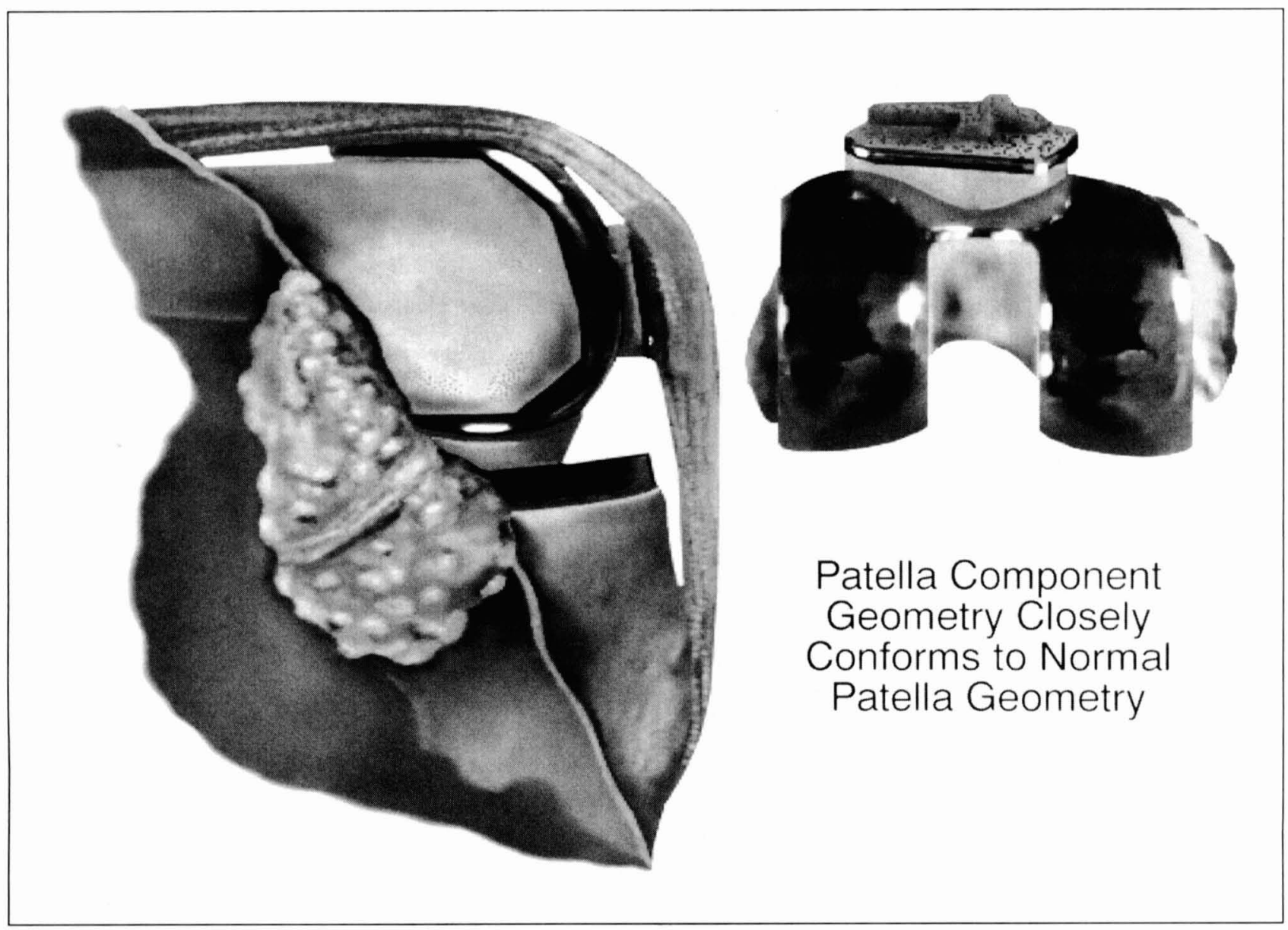

Figura 4. 
The issue of titanium vs. cobalt chrome however, remains debatable. Although titanium provides a satisfactory fixation surface, it is not acceptable as an articulating surface without specialized treatment. Cobalt chrome, therefore, remains the so-called gold standard.

\section{TECHNIQUE/BONE GRAFT ENHANCEMENT}

Implant technique varies with different TKA systems. The ultimate goal is mechanical alignment of 4-7 degrees valgus with AP, ML and patellar-femoral stability. Flexion-extension gap balance is the key to establishing stable mechanical alignment. The «femoral first» resection approach relies on estimation of the distal AP femoral cut and frequently places the femoral component in an internal rotation plane. The «tibial first» resection approach, as used in the LCS system, allows for precise distal femoral AP resection based on balanced ligament tension. The rotational position of the distal femoral component influences patellar tracking and the complex kinematics of the femoral tibial articulation, especially if the PCL is retained. Internal positioning of the femoral component, however, should be avoided!!

Biologic (fibro-osseous) integration can occur only if the implant technique is precise and porous coated surfaces are in contact with host bone or autograft. The tibia presents the challenge since the majority of failures have occurred on the tibial side. The metaphyseal, fully porocoated, tapered cone of the LCS tibial component (figure 5) has proven to be effective from a clinical standpoint. Results from multi-centered trial studies have shown less than one-percent revision for tibial loosenings (935 cementless knees with 2-8 year follow-up). Radiologic assessment has also shown that interfaces remain stable over time.

Bone graft enhancement of primary as well as revision TKA is important in achieving precise interference fit. Osteopenic bone, such as seen in rheumatoid arthritis, can be enhanced by the use of cortico-cancellous strut graft (stonehenge technique). Bone slurry or cancellous autograft can be obtained by multiple drilling or curettement. An excess of bone is available from the femoral condyle, upper tibia and patella (if resurfaced). Autograft in primary TKA is encouraged for both cementless and cemented technique on the tibial side in order to improve the biologic quality, long term fixation and survival.

\section{SUMMARY AND CONCLUSIONS}

Prosthetic fixation in TKA is dependent on many factors. Cementless implantation, primarily on the tibial side, places an added demand on surgical technique and prosthetic design to achieve predictable, long term fixation and success. Congruent articulation with moveable bearings addresses the dilemma of instability and immobility present in fixed-bearing. TKA, and decreases UHMWPe wear. Bone graft enhancement and achievement of an interference fit (with proven porous coated surfaces) are required for consistent and predictable success of cementless fixation, especially on the tibial side.

\section{REFERENCES}

1. Bert JM. Dislocation/subluxation of meniscal bearing elements after New Jersey lowcontact stress total knee arthroplasty. Clin Orthop. 1990; 254:211-215.

2. Buechel FF. Letter to the editor. Clin Orthop. 1991; 264:309 310

3. Buechel FF. Pappas MJ. New Jersey low contact stress knee replacement system: ten year evaluation of meniscal bearings. Orhop Clin North Am. 1989; 2:147-177.

4. Buechel FF, Pappas MJ. The New Jersey low contact stress knee replacement system: biomechanical rationales and review of the first 123 cemented cases. Arch Orthop Trauma Surg. 1986; 105:197-204.

5. Buechel FF, Rosa RA, Pappas MJ. A metal-backed, rotating-bearing patellar prosthesis to lower contact stress (an 11 year clinical study). Clin Orthop. 1989;248:34-49.

6. Goodfellow JW, $\mathrm{O}^{*}$ Connor JJ. Clinical results of the Oxford knee: surface arthroplasty of the tibiofemoral joint with a meniscal bearing prosthesis. Clin Orthop. 1986; 205:21-42.

7. Goodfellow JW, O'Connor JJ. The mechanics of the knee and the prosthetic design. J Bone Joint Surg. 1978; 60B:358-369.

8. Keblish PA. The lateral approach to the valgus knee: surgical technique and analysis of 53 cases over two-year evaluation. Clin Orthop. 1991; 271:52-62

9. Keblish PA, Peoples SJ. Survivosrship in Total Knee Replacement. Presented at the 55 th Annual AAOS Meeting; 1988; Atlanta, GA. 